\title{
REVIEW
}

\section{Ebola in great apes - current knowledge, possibilities for vaccination and implications for conservation and human health}

Siv Aina J. LEENDERTZ Great Apes Survival Partnership (GRASP), United Nations Environment Programme, P.O. Box 30552, Nairobi, Kenya and Research Group Epidemiology of Highly Pathogenic Microorganisms, Robert Koch-Institute, Seestrasse 10, 13353 Berlin, Germany.Email: sivaina@hotmail.com

Serge A. WICH Liverpool John Moore's University, 70 Mount Pleasant, Liverpool, Merseyside L3 5UA, UK. Email: s.a.wich@ljmu.ac.uk

Marc ANCRENAZ Borneo Futures, Taman Kinanty, Lorong Angsa 12, House 61D, 88300 Kota Kinabalu, Sabah, Malaysia.Email:marc.ancrenaz@yahoo.com

Richard A. BERGL North Carolina Zoo, 4401 Zoo Parkway Asheboro, North Carolina, USA. Email: richard.bergl@nczoo.org

Mary K. GONDER Department of Biology, Drexel University, 3245 Chestnut Street, Philadelphia,PA 19104,USA.Email: gonder@drexel.edu

Tatyana HUMLE DICE, School of Anthropology and Conservation, University of Kent, Canterbury CT2 7NR, UK. Email:T.Humle@kent.ac.uk

Fabian H. LEENDERTZ* Research group Epidemiology of Highly Pathogenic Microorganisms, Robert Koch-Institute, Seestrasse 10, 13353 Berlin, Germany. Email: LeendertzF@rki.de

*Correspondence author

\begin{abstract}
1. Ebola virus disease (EVD) is a threat to human health and to the survival of African great apes. The disease has led to major population declines in chimpanzees Pan troglodytes and gorillas Gorilla, and infected great apes play an important role as sources of human EVD
\end{abstract}


outbreaks. The threat posed by EVD raises the question whether vaccination of wild apes is an effective strategy to reduce the occurrence and impact of this disease.

2. We review the current knowledge about EVD in great apes and document the link between outbreaks in apes and in humans. We discuss the need for control strategies such as vaccination, and describe aspects of primate behaviour, virus biology, vaccine composition, and vaccination principles that need to be considered when making management decisions about great ape vaccination. Finally, we identify gaps in the understanding of Ebola ecology and highlight surveillance and research that can aid the survival of great apes and reduce human exposure to Ebola virus.

3. The unpredictable emergence of Ebola viruses and the severe impact of EVD indicate the need for efficient monitoring and, ultimately, control of Ebola. However, the unknown reservoir and unpredictable emergence of Ebola, the elusive nature of great apes, and the lack of licensed and suitable vaccines represent major hurdles for such control. With these hurdles in mind, this review provides a platform for further interdisciplinary discussions, so that management plans can be discussed and adjusted according to possible future changes in the development, availability and cost of vaccines, the status of EVD, knowledge about Ebola ecology, and opinion on wildlife vaccination.

KEY WORDS: conservation, Ebola, global health, vaccination, wild great apes

RUNNING HEAD: Ebola in great apes

Submitted: 17 April 2016

Returned for revision: 14 June 2016

Revision accepted: 5 September 2016

Editor: DR

\section{INTRODUCTION}

Ebola virus disease (EVD) is an acute, severe and lethal disease of particular concern for humans, chimpanzees Pan troglodytes, and gorillas Gorilla gorilla (Karesh \& Reed 2005, Feldmann \& Geisbert 2011). The disease is caused by viruses of the Ebola genus, belonging to the virus family Filoviridae (Kuhn et al. 2010). The Ebola genus comprises five distinct 
species, although they are generally referred to as the Ebola virus or simply Ebola. Since the first Ebola virus was discovered in 1976, Ebola viruses have sporadically re-emerged from an unknown reservoir and caused more than 20 outbreaks in humans throughout Africa (Anonymous 2015a). The epidemic that started in West Africa in December 2013 (the 20132016 EVD epidemic) has lasted for more than two years and claimed more than 11000 lives (Anonymous 2015b).

EVD is considered a major threat to the survival of African great apes, all of which are currently listed by the International Union for Conservation of Nature as Endangered or Critically Endangered (Anonymous 2016a). The disease in apes is also of concern for human health, as there is a clear link between Ebola-infected apes and human EVD outbreaks. In all eight human outbreaks in Gabon and the Republic of Congo (ROC) that have occurred in the last 25 years, there is epidemiological evidence (and in three of these outbreaks also laboratory evidence) that they were initiated by contact with infected bushmeat from gorillas or chimpanzees (Georges et al. 1999, Rouquet et al. 2005), hence hunting or scavenging of wild great apes is a major risk factor. Bats, monkeys, and perhaps other wildlife may also be able to infect humans; however, the true reservoir(s) and natural circulation of Ebola viruses still remain unidentified (Lahm et al. 2007, Olson et al. 2012, Maganga et al. 2014, Olival \& Hayman 2014, Leendertz et al. 2015, Mari Saez et al. 2015). This makes prediction, surveillance and control of EVD challenging.

The threats posed by EVD raise the question of whether vaccination of wild great apes could be a future option to help mitigate the effect of EVD on ape populations and protect human health. Although no outbreak has been confirmed in apes since 2005, the unpredictable pattern of virus emergence and the severe impact of outbreaks mean that there is concern about future occurrences.

In this review we provide an overview of what is known about EVD in great apes, and highlight surveillance and research that can aid the survival of wild great apes and reduce human exposure to Ebola virus. Moreover, we describe aspects of primate behaviour, Ebola virus biology and ecology, vaccine composition, and vaccination principles that are essential to know when considering vaccination of great apes. This article provides a platform for further interdisciplinarydiscussions to decide on optimal management solutions regarding protection of wild great apes against Ebola. 


\section{EBOLA VIRUS DISEASE}

Four separate species of Ebola virus cause EVD in Africa: Zaire EV(ZEBOV), Sudan EV (SEBOV), Cote d'Ivoire EV (TFEBOV) and Bundibugyo EV (BEBOV), of which ZEBOV and TFEBOV have so far been detected in great apes (Leroy et al. 2004, Rouquet et al. 2005, Wittmann et al. 2007, Kuhn et al. 2010). The genetic diversity of these Ebola species represents a hurdle for vaccine development, since a vaccine that is effective against one species might not protect against another (i.e. there may be a lack of cross-reaction; Feldmann \& Geisbert 2011). A fifth member of the Ebola genus (Reston EV, REBOV) exists in Asia; however, this virus is not thought to be lethal to humans, hence the EVD pathogenesis described below does not apply to it. There have been no reported cases of EVD in orang-utans Pongo spp.

The biological aspects of EVD process are similar in humans and apes (Kuhn 2008). Ebola viruses are highly infectious and enter the body through contact with mucus membranes, eyes, and broken skin. After an incubation period of 2-21 days, the infected individual develops symptoms including fever, vomiting, diarrhoea, internal bleeding, and sometimes external bleeding. There are few observations of wild apes that have presumably been suffering from EVD, but signs of abdominal pain, lethargy, poor appetite, diarrhoea and emaciation or simply abnormal behaviour have been noted in great apes, and bleeding from the nostrils has been observed among other nonhuman primates (Formenty et al. 1999, Georges et al. 1999, Lahm et al. 2007). Other individuals can get infected through contact with the body or body fluids of a sick or dead member of the social group (Warren \& Williamson 2004).

It is debated how infection can spread through ape populations over large geographical areas, and there are two main theories. The first theory is that the spread occurs solely by groupto-group infection after a single or a few introductions of the virus from the original reservoir, or from other infected animals into an uninfected ape population. Such spread could occur via direct contact, during intergroup encounters, extra-community copulation, or emigration of females (including infected gorilla females leaving the group after the death of the silverback), or indirectly, via sharing of feeding sites or home ranges (Vigilant et al. 2001, Bermejo 2004, Bradley et al. 2004). Ebola virus has been isolated in the semen of infected human males many months after infection (Chughtai et al. 2016) indicating that surviving male apes could initiate new infection chains if mating occurs within the infectious period. The potential for group-to- 
group spread in apes depends on several factors including the incubation time of the specific individual (or the longevity of infectious semen), travel distance and ape density (Walsh et al. 2007, Walsh et al. 2009, Ryan et al. 2013). The sociality of African apes, including the natural fission-fusion social system of chimpanzees (Lehmann \& Boesch 2004) may also influence the spread of virus in a positive or negative way, depending on the contact pattern and on which individuals are infected.

The second theory of how infection can spread over large areas is that outbreaks occur mainly as a direct consequence of repeated spill-over, from a so far unidentified natural host into geographically separated ape social groups. The outbreak distribution is consequently defined by the dispersal and movements of the reservoir host itself rather than by those of the apes (Leroy et al. 2004).

The two theories are not mutually exclusive; it is possible that both these modes of transmission are important, and that one or the other can predominate at times or sites depending on the underlying factors that trigger or sustain the outbreaks. In any case, Ebola's tremendous ability to spread rapidly once it has emerged is illustrated by the 2013-2016 EVD epidemic in West Africa, whichstarted with one infected child and subsequently included nearly 30000 people (Anonymous 2015c. Mari Saez et al.2015).

Experimental infections show that deaths in nonhuman primates occur within a similar time-frame as in humans (ca. 8-10 days after onset of symptoms for ZEBOV and ca. 12-14 days for TFEBOV; Geisbert et al. 2009). Although the mortality rate can be extremely high (up to $88 \%$ in humans and possibly higher in great apes infected with ZEBOV; Bermejo et al. 2006, Anonymous 2015c), it is evident that recovery and survival after infection is possible. Antibodies to Ebola virus have been detected in blood from humans, wild-born chimpanzees and other primates, and in the faeces of wild gorillas, proving that some individuals exposed to the virus can mount an immune response and recover after infection (Leroy et al. 2004, Lahm et al. 2007, Reed et al. 2014). Survival of individuals in great ape groups whose other members have died of Ebola also suggests that recovery is possible (Formenty et al. 1999, Bermejo et al. 2006); however, without laboratory testing of samples, it is not possible to ascertain whether these individuals were in fact infected or managed to escape exposure. The infectious, acute and often lethal nature of Ebola shows, however, that great apes are unlikely to be able to sustain an infection chain indefinitely. 
An outbreak stops naturally when no more susceptible individuals come into contact with infectious apes (dead or alive) or infectious materials. Leroy et al. (2004) reported that carcasses remained infectious in the rainforest for 3-4 days; it remains, however, uncertain how long the Ebola virus survives under different environmental conditions (Anonymous 2014a).

\section{OCCURENCE AND IMPACT OF EVD IN GREAT APES}

EVD in great apes was first recognised nearly twenty years after the Ebola virus was discovered in humans (Pigott et al. 2014). Ape outbreaks have mainly been detected in central Africa, whereas human outbreaks have occurred throughout tropical Africa (Figure 1).

TFEBOV was the first ape-associated Ebola species to be discovered, when 12 chimpanzees Pan troglodytes verus in the Taï National Park, Côte d'Ivoire, that were habituated to human presence died or disappeared in a few weeks in November 1994 (Formenty et al. 1999). Ebola was confirmed by immunohistology staining of virus in carcass samples and by virus isolation from a researcher who contracted EVD after exposure to the carcass. The mortality rate in the chimpanzee group was estimated to be $c a .25 \%$, similar to what has been observed in outbreaks of human BEBOV (an Ebola species not detected in apes; Towner et al. 2008). There was no further human-to-human transmission in this case and TFEBOV has not been detected again in Africa.

The ZEBOV species has had a much more significant impact on great apes. Outbreaks have occurred in North Eastern Gabon and ROC in two clusters: first in the mid-1990s and then in the first five years of this century. Surveillance of wild great apes is challenging and does not cover all wild populations, hence outbreaks could also have occurred undetected at other times. Most of what is known about the outbreaks in apes in North Eastern Gabon in the mid-1990s emanated from investigations of three human outbreaks that occurred at that time (Georges et al. 1999). In November 1994, there were concurrent reports of wildlife deaths among the local gorilla and chimpanzee populations when the first human cases appeared in gold mining camps in the Minkebé forest area. About a year later, a person butchering a dead chimpanzee found $c a .40 \mathrm{~km}$ further south initiated a second human outbreak. The third human outbreak started yet another $160 \mathrm{~km}$ further south, six months later, with the death of two hunters, of which one was said to have killed several mangabeys Cercocebus spp. before he got sick. Dead chimpanzees and gorillas were encountered on several occasions during and 
after these outbreak years, indicating that EVD affected the apes for a long time (Georges et al. 1999, Lahm et al. 2007). From these dead apes, a skin sample tested positive in Ebola immunohistology staining.

Wildlife surveys carried out in Minkebé and Mwagne forest blocks before and after these outbreak years showed a dramatic reduction (90-98\%) in the gorilla and chimpanzee populations that could have been caused by a highly lethal, rapidly spreading disease such as EVD (Huijbregts et al. 2003, Maisels et al. 2004, Lahm et al. 2007). In comparison, the mortality in humans exposed to the same virus was $59-75 \%$ in the concurrent outbreaks. The relatively lower human mortality may be due to hospital care of infected people rather than their higher biological disease resistance.

A surveillance network was subsequently set up in North Eastern Gabon and ROC due to the association between the human EVD outbreaks, the regularity of human contact with apes and/or ape meat in these countries, and the decline of great ape populations. This network, which included monitoring and sampling of a range of wildlife carcasses, revealed that five human EVD outbreaks occurring between October 2001 and May 2005 resulted from contact with infected carcasses, mainly gorillas and chimpanzees (Leroy et al. 2004, Rouquet et al. 2005, Nkoghe et al. 2011). Ebola-positive ape carcasses were found in several forest areas including Lossi and Odzala National Parks, ROC, where population losses exceeding 90\% were observed in habituated gorillas (Bermejo et al. 2006). In Lossi alone, Ebola was estimated to have killed 5000 individuals. Ebola is believed to have caused ape deaths in Odzala until at least 2007 (Caillaud et al. 2006, Cameron et al. 2016); however, since 2005, no further cases of EVD in African apes have been confirmed. A human EVD outbreak in Boende, Democratic Republic of the Congo, in 2014 might have been linked to contact with a primate carcass (species unidentified; Maganga et al. 2014); however, no samples have been obtained for testing and the link remains speculative. The human 2013-2016 EVD epidemic in West Africa is not believed to be associated with deaths of great apes or other primates, but is rather thought to be the consequence of a child's accidental contact with a large colony of insectivorous bats (Mari Saez et al. 2014). The area where the epidemic started harbours few primates, no case of dead apes has been reported, and recent surveys indicate no decline in primate populations since surveys conducted prior to the outbreak. 
In summary, EVD has probably killed thousands of gorillas and chimpanzees in the central African rainforests, where the majority of the world's remaining great ape populations reside (Vogel 2006, Hopkin 2007). In part because of these losses, the International Union for Conservation of Nature upgraded the western gorilla to Critically Endangered in 2007 (Walsh et al. 2007). Carcass samples and precise assessments of wild great ape population sizes are challenging to obtain, making it difficult to estimate the true impact of Ebola on great apes. There is, however, no reason to doubt that EVD can severely affect great ape populations. In fact, until the start of the 2013-2016 EVD epidemic in West Africa, the number of apes estimated to have succumbed to Ebola was far greater than the total number of people ( $c a$. 1500) who died from the same virus in all known human outbreaks (Anonymous 2015b).

\section{WHERE AND HOW DO APES GET INFECTED WITH EBOLA?}

It is evident from the disease's rapid spread and from the high mortality it causes in great apes that these primates are neither natural, asymptomatic carriers of the virus nor able to sustain the infection indefinitely, which are both important criteria for a reservoir host (Olival \& Hayman 2014). The apes are rather 'accidental hosts' who act as a source of infection for human outbreaks when they themselves have become infected via another host or other hosts sharing the same habitat. Numerous carcasses of other animals were found in the Gabon and ROC forests between 1994 and 2005, indicating that many species may be susceptible to EVD. The virus has only been isolated from gorillas, chimpanzees and a duiker Cephalophus sp., despite intensive testing of wildlife carcasses in outbreak areas for decades (Leroy et al. 2004, Lahm et al. 2007, Wittmann et al. 2007). Laboratory analyses of samples from certain frugivorous and insectivorous bat species indicate that they were able to host, possibly spread and indeed survive infection. However, the virus itself has never been isolated from these hosts, and more research is necessary to confirm that the virus is circulating primarily in any of these species or if yet another host represents the true reservoir (Olival \& Hayman 2014, Leendertz et al. 2015). Until the natural history and ecology of Ebola are more fully characterised, it is only possible to speculate about if and how apes (and humans) get infected from bats or other species (Viana et al. 2014). Apes are not known to hunt bats, but could potentially come into direct contact with fruit bats roosting in trees where apes feed, or with insectivorous bats roosting in tree holes where the apes search for honey, insects or water 
(Nishida 2010). Alternatively, they could get infected via excretions from any kind of bat or other animal when ingesting food contaminated with faeces, urine or saliva, although such excretion of Ebola virus in naturally infected bats is yet to be confirmed (Olival \& Hayman 2014). Direct contact with other infected hosts is another possible infection route, via hunting of monkeys or other prey that might be infected and/or during inspection of infected carcasses (Boesch \& Boesch-Achermann 2000, Karesh et al. 2012). In the chimpanzee outbreak in Côte d'Ivoire, predation of red colobus monkeys Piliocolobus badius was considered a risk factor (Formenty et al. 1999), but was not confirmed as a transmission route.

The uncertainties of Ebola ecology make predicting outbreaks in wildlife (and humans when no previous wildlife outbreak is detected) nearly impossible, and without further data most of the tropical belt of Africa is considered a risk area for Ebola emergence (Pigott et al. 2014). This has implications for outbreak preparedness in humans and wildlife alike. What is clear, however, is that apes are intermittently exposed to Ebola viruses in their natural environment, which means that we might not be able to remove, or prevent exposure to, the source of infection. This highlights the need for considering strategies to prevent the infection of great apes, and to also break the link between them and human EVD outbreaks (Feldmann \& Geisbert 2011).

\section{PREVENTING OR REDUCING THE SPREAD OF EBOLA IN APE POPULATIONS}

Considering the severe reduction in population number and dissemination of groups that follows EVD outbreaks in great apes, it is highly questionable whether leaving this disease to be regulated by nature itself is a viable option. Demographic structure changes (for example increased frequency of emigration to start new breeding groups) in populations after severe declines can occur, and may favour population growth (Genton et al. 2012, Genton et al. 2014, Reed et al. 2014). However, in the case of repeated outbreaks and added pressure from other infectious diseases, bushmeat hunting and deforestation, these recovery strategies might not be sufficient to prevent extinction (Leendertz et al. 2006, Morgan \& Sanz 2007, Kondgen et al. 2008, N'Goran et al.2012). Apes have a relatively long generation time (Anonymous 2014a), which means that an outbreak of a disease with a high mortality rate such as EVD requires a very long recovery time for affected populations. It may take the affected gorilla population in Lossi more than 130 years to recover to its initial size (Ryan \& Walsh 2011). In 
addition, fragmentation of populations due to mortality has a negative impact on the genetic diversity of the populations, which could exacerbate extinction risk especially when populations are reduced in size. Therefore, it is clear that efficient strategies to reduce the impact of EVD on wild populations are beneficial for conservation. Further, prevention or reduction of infectious diseases in wildlife, including preservation of natural ecosystem integrity and biodiversity, ultimately has a positive impact on human health (Rabinowitz et al. 2013). However, not all human EVD originated from infected great apes, and such strategies will not prevent human exposure to Ebola viruses from other wildlife sources (Anonymous 2015a).

The question that arises when any wildlife is concerned, is if any intervention in a natural ecosystem is justified. The benefits of any intervention must be assessed in conjunction with the potential negative impacts (Fedigan 2010, Gruen et al. 2013). Nearly all great ape populations have been, and continue to be, affected by humans, so that apart from in some protected areas, the majority of the African forests can no longer be considered 'natural' (Laurance 2009, Hockings et al. 2015). Preserving protected species is required by law and there should be an additional moral responsibility to preserve endangered species. Humaninduced environmental changes such as deforestation and urbanisation may also exacerbate the likelihood of Ebola virus emergence (Waldman 2015). Hence it seems rational to focus on how to protect the remaining wild great apes from a disease that is incompatible with the survival of the species should outbreaks continue to occur, rather than on whether human intervention is justified. Hypothetical possibilities to prevent the spread of Ebola within ape populations exist, but the question of which strategy or strategies are feasible and efficient, despite limited knowledge about the natural ecology of these viruses and their unpredictable emergence, remains.

In human EVD outbreaks, isolation of infected cases remains an important control strategy (Anonymous 2015d). Protection of the great apes cannot rely upon similar isolation strategies, although it might naturally occur to some degree as apes sometimes temporarily leave the rest of the social group when experiencing signs of disease (Boesch \& BoeschAchermann 2000). It is evident that some isolated groups of chimpanzees and gorillas continue to thrive when separated, in one instance only by $20 \mathrm{~km}$, from an outbreak area (Lahm et al. 2007), hence geographical separation could theoretically provide protection. However, attempting to isolate social groups by cutting corridors in the forest in order to stop the spread 
of infected apes is unlikely to be feasible, desirable or efficient for various reasons. Firstly, clearing of large geographical areas in dense and remote rainforest areas is labour intensive and in conflict with forest preservation, and as apes are able to cross large open areas, the effort might not even be worthwhile (Haurez et al. 2013). Further, should separation be successful it might create stress for the apes due to human disturbance and changes in their territory, and in the long term compromise the population's genetic viability. Finally, the virus could be introduced to other parts of the forest by reservoir hosts not restricted by human-made barriers, which make attempts to separate ape groups geographically to avoid the spread of infection redundant.

Preliminary results regarding experimental post-exposure treatments based on protective antibodies (e.g. ZMapp) are encouraging; however, patients require additional intensive care, hence such medication is unlikely to be effective in controlling EVD outbreaks in wild apes, even when they are habituated. Vaccination, i.e. administration of preventative medication which stimulates an immune response that will protect the individuals against natural exposure to the virus, could be the most promising control strategy in great apes. Indeed, the prospect of safe and efficient Ebola vaccines in the near future invites a discussion about their use in wild populations of great apes (Marzi \& Feldmann 2014). There are significant ethical issues when considering the vaccination of wild great apes; even in humans the prospective use of vaccines is not without ethical and practical concerns (Cohen \& Kupferschmidt 2014, Lee et al. 2015).

Vaccines have been used in wild apes (Ryan \& Walsh 2011). For example, small-scale vaccination against diseases like measles, poliomyelitis, tetanus, and anthrax has been done in habituated (or reintroduced) populations (Goodall 1986, Hastings et al. 1991, Ryan \& Walsh 2011). Vaccinations were done through distance darting, injections when other interventions were undertaken under general anaesthesia, or, in the case of chimpanzee poliomyelitis in the mid-1960s, through feeding of bananas; an acceptable practice at the time.

\section{VACCINATING WILD GREAT APES AGAINST EBOLA}


Implementation of great ape vaccination programs seems superficially straightforward, since humans and great apes are genetically and physiologically similar and exhibit similar immunological reactions to vaccines. However, the limited accessibility of great apes due to their elusive nature and occurrence in remote habitats limits the choice of vaccine and means that carefully considered vaccination strategies are needed. A thorough understanding of EVD, the great apes' natural behaviour, and the vaccines that might become available in the future is required to discuss and decide on appropriate vaccination strategies.

\section{Current vaccine candidates}

In the last few decades, a number of vaccine types have been tested in suitable animal models, including in nonhuman primates, and some have subsequently advanced into human clinical trials (Marzi \& Feldmann 2014, Falzarano 2016). Regardless of whether a vaccine is intended for use in humans or in great apes, it is extremely important to ensure its safety; crisis situations should not bypass the need to establish a vaccine's risk-benefit profile and to address both real and perceived safety concerns (Lee et al. 2015, Rougeron et al. 2015).

To understand the possible use and limitations of vaccines in great apes (and humans), it is essential to understand that vaccine candidates differ in their composition; defining socalled different vaccine platforms (Marzi \& Feldmann 2014). The composition of the vaccine determines which type and degree of immune reaction it stimulates, and if a vaccine needs to be injected rather than administered via other routes to induce sufficient protection from infection. Subsequently, this decides the type and number of interventions necessary at the individual or population level to induce protection, and how long this protection lasts.

Several Ebola vaccine candidates are vector-based vaccines consisting of some type of relatively benign virus that has been genetically modified to display Ebola-specific antigens on the surface. In this way, the vector virus presents itself as Ebola virus to the vaccinated host, and activates an appropriate immune response as long as it is viable. Such vaccine candidates include $c A d 3-E B O-Z$ and $r V S V-Z E B O V$, which have both proven to be protective after one single injection in nonhuman primates and are currently in human trials(Henao-Restrepo et al. 2015, De Santis et al. 2016). rVSV-ZEBOV can be used when the individual is already infected with Ebola, and an important feature which might be relevant for its use in wild apes 
is that oral immunization with this vaccine has proven possible, at least in the rodent and nonhuman primate models, suggesting that baiting of vaccine is in theory possible (Qiu et al. 2009).

Another type of vector-based vaccine candidate is Cytomegalovirus-based vaccine (CMV vaccine; Marzi et al. 2016). In contrast to the other candidates, this vaccine is intended specifically for wild great apes, and is designed to be able to spread from one individual to another (Figure 2a). Ideally the vaccine virus should be given to relatively few individuals and subsequently spread through the population indefinitely whilst stimulating protection against Ebola. However, the ethics and risks of introducing any genetically modified virus, even if the original vector virus is naturally found in the population, require careful and thorough discussion (Tsuda et al. 2011, Murthy et al. 2013). Once released, the vaccine-virus cannot be removed from the population.

A vaccine with fewer safety concerns is Virus Like Particles-vaccine; it does not include any virus component but rather consists of a genetically engineered protein product that mimics the structure of Ebola virus (Marzi \& Feldmann 2014). Studies in nonhuman primates, including captive chimpanzees, show that multiple injections are required to reach full potency of the vaccine, hence there are doubts about the use of this vaccine in the wild (Warfield et al. 2014).

Additional candidates have proven protective in nonhuman primate models and vaccine research is currently progressing rapidly, hence further candidates and possibly additional administration routes are likely to appear in the future (Bukreyev \& Collins 2010, Geisbert 2015).

\section{Possible vaccination strategies}

The different properties of the vaccines determine how they can be administered, how many individuals might be protected after a single intervention, and how long protection lasts. The selection of a vaccine and a cost-effective vaccination strategy is therefore mainly determined by the accessibility of the apes, i.e. whether they are habituated to human presence or not, and by the aim of vaccination, e.g. to prevent introduction of Ebola from the natural source into the ape population, or to stop the spread of infection within populations once an outbreak has 
started. Wild apes that have been habituated for behavioural research or tourism are observed on a regular basis, and individual apes are usually identified. This means that initial vaccination, monitoring and follow-up vaccination are, in theory, possible. Unhabituated apes are not accessible for such treatment. Most apes in Africa are not habituated, although in some small populations a relatively large percentage is habituated (e.g. ca. $70 \%$ in the Virunga Mountain Gorillas; Robbins et al. 2011). However, habituated apes and sanctuary apes (Anonymous 2016b) are wild endangered species, and should therefore not be used to test experimental vaccinations. The population size, location, and even existence of unhabituated apes might not be known, hence gaining access to these apes and monitoring vaccination coverage is a real challenge.

For these reasons, it is possible that different vaccines and strategies are suitable according to the specific population in question. Strategies are discussed below in general terms without referring to current vaccine candidates, as additional candidates are likely to become available in future (Figure 2).

\section{PREVENTION OF EBOLA SPILL-OVER INTO HABITUATED POPULATIONS BY VACCINATION}

As the number of habituated great apes is relatively small, it may be possible to vaccinate all or at least the majority of them (Figure $2 b$ ), provided funding is available. If not, individuals that are important for reasons such as breeding potential and/or disease spreading ability within the social network must be selected according to the species and demographic structure for the population in question (Carne et al. 2013). However, as long as the ecology and transmission of Ebola from the natural reservoir is not determined, high-risk individuals within a group cannot be identified.

The more or less constant proximity of habituated apes to humans makes darting a possible route of vaccine administration for them. Although it can be challenging and dangerous for the apes and personnel, darting yields a high degree of certainty that the vaccine has been received. Ideally, a vaccine that protects after a single administration should be used, to avoid excessive darting that might also have a negative impact on years or decades of habituation efforts. For the same reason, the vaccine (with or without the required booster) should induce long-lasting protection. The vaccine candidates that are presently in human trials 
are considered to induce long-term protection sufficient to last for the duration of a human outbreak, but protection for months or even a couple of years might not be optimal for longterm prevention of EVD in wild apes (Stanley et al. 2014, Wong et al. 2014). If a safe, efficient and ethically accepted self-spreading vaccine becomes available for use in great apes (as suggested by Marzi et al. 2016), relatively few individuals will require darting to induce high level of vaccination cover and longevity of protection in a population (Figure 2a).

Baiting is, in theory, another option for vaccine delivery to habituated apes, provided the vaccine is designed to induce protection after oral administration. However, apes are selective in what they eat, so it might be difficult to ensure that all individuals receive the vaccine, or to prevent one or a few dominant individuals from consuming higher vaccine doses than intended (Ryan \& Walsh 2011). Furthermore, feeding wild great apes with food items that might be desirable but foreign to them, e.g. bananas, is no longer a generally accepted practice. However, the benefits of such provisioning for vaccination purposes might outweigh the costs.

\section{CONTROL OF EVD OUTBREAKS IN HABITUATED POPULATIONS}

Trying to vaccinate by darting during a great ape Ebola outbreak is likely to be stressful and dangerous for human personnel and apes. Human safety must be addressed in planning any intervention, whether the ape population is habituated or not. Further, the rapid progression of disease and death leaves little time to vaccinate, which makes it essential to follow a logistically feasible vaccination priority list to prevent further spread of infection. A 'ring vaccination' (Figure 2c) of in-contact individuals and individuals in surrounding unaffected populations could be attempted (Henao-Restrepo et al. 2015). This approach might, however, not be fast or efficient enough to stop the outbreak, and the virus could be introduced directly from the reservoir to unaffected apes on the outside of the vaccination borders (Leroy et al. 2004). In an outbreak situation, it would be beneficial to use a vaccine that is effective also when an individual is already infected. Protection induced by a potential self-spreading vaccine (Figure 2a) requires that the vaccine vector spreads and induces protection faster than the Ebola virus itself spreads. It would make more sense to use such a vaccine well before an outbreak situation, but it could be beneficial if it was used in parallel with other vaccinations as an extension of a ring vaccination strategy. 
An outbreak of Ebola in great apes might be accompanied by human cases. If there is low availability of vaccines developed for human use, the costs, benefits and ethics of using these valuable doses on wildlife should be considered.

\section{PREVENTION OF EBOLA SPILL-OVER INTO NON-HABITUATED POPULATIONS BY VACCINATION}

The aim of such vaccination would be to protect the entire population from introduction of Ebola virus (2d), however the elusive nature of non-habituated apes poses a considerable obstacle to administering injectable vaccines, and it is questionable whether vaccinating randomly encountered individuals would be sufficient to protect populations of apes throughout Africa, especially if the vaccination would require booster injections after some time. The cost-benefit must be modelled for the individual populations, including factors such as to what proportion of the population can be expected to be reached, and the perceived risk of viral spill-over in the area. The unpredictable emergence of Ebola from its reservoir makes such risks difficult to estimate. Although only relatively specific areas in North Eastern Gabon, ROC and Cote d'Ivoire have proven to be ecologically suitable for transmission of Ebola into great ape populations, the majority of the tropical belt of Africa is currently considered to be a risk area for viral emergence (Pigott et al. 2014, Walsh \& Haseeb 2015).

Baiting does not require close-range contact with individuals, but poses the same challenges as described for habituated apes and also requires efficient administration on a much larger geographical scale. A self-spreading vaccine that would require relatively few interventions and that could, in theory, provide widespread protection against Ebola may seem promising for remote, non-accessible populations, but the safety and ethics of such an approach must be addressed.

Other ideas are to develop efficient fog sprays or environmental vaccines that can be administered to larger areas of remote ape habitats, or, when the ecology of Ebola is better understood, to vaccinate species that the apes could contract Ebola infection from.

\section{CONTROL OF EVD OUTBREAKS IN NON-HABITUATED POPULATIONS}

Firstly, outbreaks of Ebola in unmonitored ape populations are likely to go unnoticed, or to be recognised only when they are large enough to be detected via wildlife surveys, unless there is 
an efficient hunter surveillance network already in place. Secondly, for reasons discussed above, reaching and vaccinating enough unhabituated individuals in order to control a rapidly spreading outbreak is unlikely to be possible. Ring vaccination of unaffected habituated groups might be considered, in order to prevent the spread of infection to groups outside of the ring, or to protect particularly vulnerable groups within the ring.

\section{CHALLENGES AND FEASABILITY OF EFFICIENT VACCINATION OF WILD}

\section{APES}

There are currently a number of challenges to be overcome before vaccination of apes against Ebola can be efficient from a conservation perspective. Nevertheless, strategies should be formulated and discussed based on up-to-date knowledge and the prospects of future advances in vaccine development, to prepare financially and logistically for possible rapid changes in vaccine availability. This needs to be done for each specific population, to accommodate for differences in species, population size, habituation status, accessibility and other factors relevant to the countries in question. Management plans can be discussed and adjusted according to changes in the development, availability and cost of vaccines; disease situation;

knowledge about Ebola ecology; and opinion on wildlife vaccination. To this end, interdisciplinary meetings including representatives from the fields of primatology, wildlife conservation, ecology, epidemiology, virology, immunology and public health are necessary, so that researchers can discuss and find well-considered solutions for this complex problem. These discussions should also include how to record details of any vaccination attempt and how to monitor the effect in a scientific way (Travis et al. 2008). The more data that are available, the better we can implement disease models and adjust future disease prevention strategies.

\section{GREAT APE HEALTH MONITORING, RESEARCH AND DISEASE AWARENESS}

Irrespective of whether future strategies for preventing Ebola will be implemented or not, monitoring great ape health in itself is important and should be included in conservation plans, together with poaching control and habitat protection (Travis et al. 2006). Further, the fact that apes and humans alike are highly susceptible to Ebola make the great apes important sentinels for human disease, therefore monitoring mortality in these wildlife hosts, and collecting 
samples for pathogen identification, may allow us to predict and possibly prevent zoonotic transmission into humans (Calvignac-Spencer et al. 2012). It is the responsibility of any conservation and research project staff to take wildlife death seriously, to develop protocols in the event of a disease outbreak, and to report cases even if the project itself is not concerned with great ape health. This should go hand in hand with raising public awareness about the risk of hunting and scavenging apes and highlighting the importance of hunters and other villagers reporting dead apes, perhaps via the chiefs of the villages to the local health authorities. During the first bout of human outbreaks in Gabon in the 1990s, lack of awareness of the role of great apes in Ebola outbreaks limited the epidemiological and laboratory investigation of these species. The need for wildlife monitoring was subsequently recognised, and in the next series of outbreaks some years later a well-prepared wildlife monitoring network was able to warn the health authorities about the risk of human cases. Sampling of carcasses led to the confirmation of infected apes and duikers as the source of the human outbreaks (Rouquet et al. 2005).

Great ape monitoring should be done in a systematic and quantitative manner by qualified personnel, such as veterinarians that have been trained to perform wild animal necropsies under highly stringent safety conditions. Such monitoring has been shown to be a prerequisite for the early detection and effective sampling of suspected cases of EVD (Leendertz et al. 2006, Travis et al. 2008); laboratory analysis is the only way to confirm Ebola infection. Antibody testing of non-invasively collected great ape samples can show which populations have been exposed to the virus, and surveys to estimate group density and population numbers may provide information about population declines possibly caused by Ebola (Campbell et al. 2008, Kouakou et al. 2009, Olson et al. 2012, Reed et al. 2014, Cameron et al. 2016). Identification of the virus's true reservoir and infection pathways in nature remains important research (Leendertz 2016). This emphasises the need for continuous funding and recruitment of people involved with disease monitoring, ranging from veterinarians to field primatologists, project managers, ecologists, and laboratory workers. We encourage the involvement of researchers and laboratories in great ape countries for increased sustainability of such work.

Although not all human EVD outbreaks that have occurred can be linked to deaths in great apes, it is clear that contact with bushmeat from any species of great ape, either via 
hunting, scavenging or butchering, is a major risk factor for exposure to Ebola virus (Feldmann \& Geisbert 2011, Anonymous 2014c). This epidemiologically and laboratory-confirmed transmission pathway should be a reminder that hunting animals that may be infected with Ebola virus can increase the risk of human outbreaks. Continuous public education by health and conservation organizations in great ape countries remains an important and priority task for disease prevention; a good example is the hunter surveillance and public health programme in Northern Congo (Anonymous 2015e). Such outreach programmes that communicate, in a culturally sensitive way, the dangers of handling bushmeat enhance awareness of zoonotic infections from great apes and other wildlife. Although reducing the handling of bushmeat will not affect the occurrence of EVD in apes, there may be indirect benefits to conservation. Possible risks of disease transmission between apes and humans must also be conveyed to tourists that are in relatively close contact with wild great apes in tourism-for-conservation projects (Muehlenbein \& Ancrenaz 2009, Macfie \& Williamson 2010).

\section{WHAT TO DO IF EBOLA IS SUSPECTED OR CONFIRMED IN APES?}

This review is not meant as a manual for the collection and analysis of data and samples; for this we refer to other guidelines for great ape health monitoring (Gilardi et al. 2015). The Ebola virus is highly infectious and lethal, and represents a major risk to human health; well-meaning, unskilled or unprotected investigators or tourists, as well as highly-trained public health workers, might risk their own life and possibly initiate a human outbreak if they encounter an infected animal. The rapid decomposition of carcasses in the rainforest means that finding even a single carcass in the rainforest should raise awareness, as this individual might be one of many other undetected carcasses, and an immediate and intensive search should be initiated. Whenever an ape carcass is detected, especially if Ebola is suspected, the wildlife authorities and the local ministry of health should be informed, following the ROC surveillance guidelines (Reed et al. 2014). Necropsy samples should only be taken by specialists trained for these situations, and anybody in direct or indirect contact with carcasses must adhere to the highest standards for protective clothing and disinfection (Leendertz et al. 2006, Ringen et al. 2015).

The possibility and limitations of vaccination in an outbreak situation, as described above, should ideally have been discussed well beforehand and a network of assistance for 
such emergency situations should be established. Finally, openly sharing experiences after an outbreak is crucial for improving preparedness for future outbreaks.

\section{CONCLUSION}

Ebola viruses can cause large epidemics in humans and great apes. The likelihood that these viruses will continue to emerge unpredictably in tropical Africa highlights the necessity to protect apes from the severe impact of EVD and to reduce human contact with infected wildlife sources. Further research is required to determine the natural circulation of Ebola viruses and the mechanisms facilitating viral emergence; however, bushmeat from infected apes is confirmed as a source of infection for human outbreaks, hence public education about zoonotic diseases and monitoring of great ape healthremain important human outbreak prevention strategies. With the rapid progress in Ebola vaccine development, vaccination of wild great apes might become a tool for conservation and protection of human health in the future. Research must focus on developing safe and efficient vaccines that can be delivered efficiently to large populations of elusive wild apes in their natural remote habitats. A thorough understanding of the disease and of the great apes' natural behaviour, as well as knowledge of the properties of vaccine candidates is necessary to assess the feasibility of potential vaccination programs.

\section{ACKNOWLEDGEMENTS}

All authors discussed the content and design of the manuscript; SAJL searched the literature, wrote the paper, designed the figures; SAW, MA, RAB, MKG, TH and FHL wrote the paper; all authors agreed on the final version of the manuscript. This study was commissioned and funded by the United Nations Environmental Programme Great Apes Survival Partnership (GRASP). We thank Charles Emil for the assistance with the figures. Special thanks to Laura Darby and Nicolien de Lange for their assistance in editing the manuscript.

\section{REFERENCES}

Anonymous (2014a) State of the Apes: Extractive Industries and Ape

Conservation. Cambridge University Press, Cambridge, UK. 
Anonymous (2014b) Regional Action Plan for the Conservation of Western Lowland Gorillas and Central Chimpanzees 2015-2025. IUCN, Gland, Switzerland.

Anonymous (2014c) An update on the risk of transmission of Ebola virus (EBOV) via thefood chain. European Food Safety Authority Journal 12: 25.

Anonymous (2015a) Centre for Disease Control and Prevention. Outbreaks chronology: Ebola Virus Disease. http://www.cdc.gov/vhf/ebola/outbreaks/history/chronology.html.

Anonymous (2015b) World Health Organisation Ebola virus disease factsheet. http://www.who.int/mediacentre/factsheets/fs103/en/.

Anonymous (2015c) World Health Organisation Ebola Situation Reports. http://apps.who.int/ebola/en/ebola-situation-reports.

Anonymous (2015d) World Health Organisation. Manual for the care and management of patients in Ebola Care Units/ Community Care Centres. http://apps.who.int/iris/bitstream/10665/149781/1/WHO_EVD_Manual_ECU_15.1_ eng.pdf?ua=1.

Anonymous (2015e) Wildlife Conservation Society. http://www.wcs.org/conservationchallenges/wildlife-health/disease-investigations/ebola.aspx.

Anonymous (2016a) The IUCN Red List of Threatened Species. http://www.iucnredlist.org/.

Anonymous (2016b) Pan African Sanctuaries Alliance http://www.pasaprimates.org Bermejo M (2004) Home-range use and intergroup encounters in western gorillas (Gorilla g. gorilla) at Lossi forest, North Congo. American Journal of Primatology 64: 223-232.

Bermejo M, Rodriguez-Teijeiro J D, Illera G, Barroso A, Vila C, Walsh PD (2006) Ebola outbreak killed 5000 gorillas. Science 314: 1564. 
Boesch C,Boesch-Achermann H (2000) The Chimpanzees of the Taï Forest: Behavioural Ecology and Evolution. Oxford University Press, Oxford, UK.

Bradley BJ, Doran-Sheehy D M, Lukas D, Boesch C, Vigilant L (2004) Dispersed male networks in western gorillas. Current Biology 14: 510-513.

Bukreyev A, Collins PL (2010) Filovirus vaccines: what challenges are left? Expert Review of Vaccines 9: 5-8.

Caillaud D, Levréro F, Cristescu R, Gatti S, Dewas M, Douadi M, Gautier-Hion A, Raymond M, Ménard N (2006) Gorilla susceptibility to Ebola virus: the cost of sociality. Current Biology 16: 489-491.

Calvignac-Spencer S, Leendertz SA, GillespieTR, Leendertz FH (2012) Wild great apes as sentinels and sources of infectious disease. Clinical Microbiology and Infection 18: 521-527.

Cameron KN, Reed P, Morgan DB, Ondzie AI, Sanz CM, Kühl HS, Olson SH, Leroy E, Karesh WB, Mundry R (2016) Spatial and temporal dynamics of mortality event among central African great apes. PLOS One 11(5): e0154505

Campbell G, Kuehl H, N'Goran K, Boesch C (2008) Alarming decline of West African chimpanzees in Cote d'Ivoire. Current Biology 18: 903-904.

Carne C, Semple S, Morrogh-Bernard H, Zuberbühler K, Lehmann J (2013) Predicting the vulnerability of great apes to disease: the role of superspreaders and their potential vaccination. PLOS One 8: e84642

Chughtai AA, Barnes M, Macintyre CR (2016) Persistence of Ebola virus in various body fluids during convalescence: evidence and implications for disease transmission and control. Epidemiology and Infection 25: 1-9. 
Cohen J, Kupferschmidt K (2014) Infectious diseases. Ebola vaccine trials raise ethical issues. Science 346: 289-290.

De Santis O, Audran R, Pothin E, Warpelin-Decrausaz L, Vallotton L, Wuerzner G et al. (2016) Safety and immunogenicity of a chimpanzee adenovirus-vectored Ebola vaccine in healthy adults: a randomised, double-blind, placebo-controlled, dose-finding, phase 1/2a study. Lancet Infectious Disease 16: 311-320.

Falzarano D (2016) Ebola vaccines: we have options. Lancet Infectious Disease 16: 267-268.

Fedigan LM (2010) Ethical issues faced by field primatologists: asking the relevant questions. American Journal of Primatology 72: 754-771.

Feldmann H, Geisbert TW (2011) Ebola haemorrhagic fever. The Lancet 377: 849-862.

Formenty P, Boesch C, Wyers M, Steiner C, Donati F, Dind F, Walker F, Le Guenno B (1999) Ebola virus outbreak among wild chimpanzees living in a rain forest of Cote d'Ivoire. Journal of Infectious Diseases 179: 120-126.

Geisbert TW (2015) Emergency treatment for exposure to Ebola virus: the need to fast-track promising vaccines. Journal of the American Medical Association 313: 1221-1222.

Geisbert TW, Geisbert JB, Leung A, Daddario-DiCaprio KM, Hensley LE, Grolla A, Feldmann H (2009) Single-injection vaccine protects nonhuman primates against infection with Marburg virus and three species of Ebola virus. Journal of Virology 83: 7296-7304.

Genton C, Cristescu R, Gatti S, Levréro F, Bigot E, Caillaud D, Pierre J-S, Ménard N (2012) Recovery potential of a western lowland gorilla population following a major Ebola outbreak: results from a ten-year study. PLoS One 5: e37106. 
Genton C, Pierre A, Cristescu R, Lévréro F, Gatti S, Pierre J-S, Ménard N, Le Gouar P (2015) How Ebola impacts social dynamics in gorillas: a multistate modelling approach. Journal of Animal Ecology 84: 166-176.

Georges A-J, Leroy EM, Renaut AA, Benissan CT, Nabias RJ, Ngoc MT et al. (1999) Ebola hemorrhagic fever outbreaks in Gabon, 1994-1997: epidemiologic and health control issues. Journal of Infectious Disease 179: 65-75.

Gilardi KV, Gillespie TR, Leendertz, FH, Macfie EJ, Travis DA, Whittier CA, Williamson EA (2015) Best Practice Guidelines for Health Monitoring and Disease Control in Great Ape Populations. ICUN SSC Primate Specialist Group, Gland, Switzerland.

Goodall J (1986) The Chimpanzees of Gombe: Patterns of Behaviour. Harvard University Press, Cambridge, UK.

Gruen L, Fultz A, Pruetz J (2013) Ethical issues in African great ape field studies. Institute for Laboratory Animal Research Journal 54: 24-32.

Hastings BE, Kenny D, Lowenstine LJ, Foster JW (1991) Mountain gorillas and measles: ontogeny of a wildlife vaccination program. Proceedings of American Association of Zoo Veterinarians 198-205.

Haurez B, Petre CA, Doucet JL (2013) Impacts of logging and hunting on western lowland gorilla (Gorilla gorilla gorilla) populations and consequences for forest regeneration. A review. Biotechnologie, Agronomie, Société et Environnement 17: 364-372.

Henao-Restrepo AM, Longini IM, Egger M, Dean NE, Edmunds WJ, Camacho A et al. (2015) Efficacy and effectiveness of an rVSV-vectored vaccine expressing Ebola surface glycoprotein: interim results from the Guinea ring vaccinationcluster-randomised trial. Lancet 386: 857-866. 
Hockings KJ, McLennan MR, Carvalho S, Ancrenaz M, Bobe R, Byrne RW et al. (2015) Apes in the anthropocene: flexibility and survival. Trends in Ecology and Evolution 30: 215222.

Hopkin M (2007) Gorillas on the list. Nature 449: 127.

Huijbregts B, Wachter PD, Ndong Obiang LS, Akou ME (2003) Ebola and the decline of gorilla (Gorilla gorilla) and chimpanzee (Pan troglodytes) populations in Minkebe Forest, north-eastern Gabon. Oryx 37: 437-443.

Karesh W, Reed P (2005) Ebola and great apes in Central Africa: current status and future needs. Bulletin de la Société de Pathologie Exotique 98: 237-238.

Karesh WB, Dobson A, Lloyd-Smith JO, Lubroth J, Dixon MA, Bennett M et al. (2012) Ecology of zoonoses: natural and unnatural histories. Lancet 380: 1936-1945.

Kondgen S, Kuhl H, N'Goran PK, Walsh PD, Schenk S, Ernst N et al. (2008) Pandemic human viruses cause decline of endangered great apes. Current Biology 18: 260-264.

Kouakou CY, Boesch C, Kuehl H (2009) Estimating chimpanzee population size with nest counts: validating methods in Tai National Park. American Journal of Primatology 71: 447457.

Kuhn JH (2008) Filoviruses. A compendium of 40 years of epidemiological, clinical, and laboratory studies. Archives of Virology Supplement 20: 13-360.

Kuhn JH, Becker S, Ebihara H, Geisbert TW, Johnson KM, Kawaoka Y et al. (2010) Proposal for a revised taxonomy of the family Filoviridae: classification, names of taxa and viruses, and virus abbreviations. Archives of Virology 155: 2083-2103. 
Lahm SA, Kombila M, Swanepoel R, Barnes RF (2007) Morbidity and mortality of wild animals in relation to outbreaks of Ebola haemorrhagic fever in Gabon, 19942003. Transactions of the Royal Society of Tropical Medicine and Hygiene 101: 64-78.

Laurance WF, Goosem M, Laurance SGW (2009) Impacts of roads and linear clearings on tropical forests. Trends in Ecology and Evolution 24: 659-669.

Lee BY, Moss WJ, Privor-Dumm L, Constenla DO, Knoll MD, O'Brien KL (2015) Is the world ready for an Ebola vaccine? Lancet 385: 203-204.

Leendertz FH, Pauli G, Maetz-Rensing K, Boardman W, Nunn C, Ellerbrok H, Jensen SA, Junglen S, Boesch C (2006) Pathogens as drivers of population declines: the importance of systematic monitoring in great apes and other threatened mammals. Biological Conservation 131: 325-337.

Leendertz SAJ (2016) Testing new hypotheses regarding Ebolavirus reservoirs. Viruses 8(2) doi:10.3390/v8020030

Leendertz SA, Gogarten JF, Düx A, Calvignac-Spencer S, Leendertz F (2016) Assessing the evidence of fruit bats as the reservoir for Ebola viruses. Ecohealth 13: 18-25.

Lehmann J, Boesch C (2004) To fission or to fusion: effects of community size on wild chimpanzee (Pan troglodytes verus) social organisation. Behavioural Ecology \& Sociobiology 56: 207-216

Leroy EM, Rouquet P, Formenty P, Souquiere, S, Kilbourne A, Froment JM et al. (2004) Multiple Ebola virus transmission events and rapid decline of central African wildlife. Science 303: 387-390. 
Leroy EM, Telfer P, Kumulungui B, Yaba P, Rouquet P, Rougues P, Gonzales JP, Ksiazek TG, Rolling PE, Nerrienet E (2004) A serological survey of Ebola virus infection in central African nonhuman primate. Journal of Infectious Diseases 190:1895-1899.

Macfie EJ, Williamson EA (2010) Best Practice Guidelines for Great Ape Tourism. IUCN/SSC Primate Specialist Group, Gland, Switzerland.

Maganga GD, Kapetshi J, Berthet N, Ilunga BK, Kingebeni PM et al. (2014) Ebola virus disease in the Democratic Republic of Congo. New England Journal of Medicine 371: 208391

Maisels F, Ella Akou M, Douckaga M, Moundounga A (2004) Mwagne National Park, Gabon: Large Mammals and Human Impact. WCS/WWF, Gabon.

Mari Saez A, Weiss S, Nowak K, Lapeyre V, Zimmermann F, Dux A et al. (2014) Investigating the zoonotic origin of the West African Ebola epidemic. EMBO Molecular Medicine 7: 17-23.

Marzi A, Feldmann H (2014) Ebola virus vaccines: an overview of current approaches. Expert Review of Vaccines 13: 521-531.

Marzi A, Murphy AA, Feldmann H, Parkins CJ, Haddock E, Hanley PW et al. (2016) Cytomegalovirus-based vaccine expressing Ebola virus glycoprotein protects nonhuman primates from Ebola virus infection. Scientific Reports 6: 21674.

Morgan D, Sanz C (2007) Best Practice Guidelines for Reducing the Impact of Commercial Logging on Great Apes in Western Equatorial Africa. ICUN SSC Primate Specialist Group, Gland, Switzerland.

Muehlenbein MP, Ancrenaz M (2009) Minimizing pathogen transmission at primate ecotourism destinations: the need for input from travel medicine. Journal of Travel Medicine 16: 229-232. 
Murthy S, Couacy-Hymann E, Metzger S, Nowak K, De Nys H, Boesch C, Wittig R,Jarvis MA, Leendertz FH, Ehlers B (2013) Absence of frequent herpesvirus transmission in a nonhuman primate predator-prey system in the wild. Journal of Virology 87: 10651-10659.

N'Goran PK, Boesch C, Mundry R, N'Goran EK, Herbinger I, Yapi FA, Kühl HS. (2012) Hunting, law enforcement, and African primate conservation. Conservation Biology 26: 565571.

Nishida T, Zamma K, Matsusaka T, Inaba A (2010) Chimpanzee Behavior in the Wild. Springer, Tokyo, Japan.

Nkoghe D, Kone ML, Yada A, Leroy E (2011) A limited outbreak of Ebola haemorrhagic fever in Etoumbi, Republic of Congo, 2005. Transactions of the Royal Society of Tropical Medicine and Hygiene 105: 466-472.

Olival KJ, Hayman DT (2014) Filoviruses in bats: current knowledge and future directions. Viruses 6: 1759-1788.

Olson SH, Reed P, Cameron KN, Ssebide BJ, Johnson CK, Morse SS, Karesh WB, Mazet JAK, Joly DO (2012) Dead or alive: animal sampling during Ebola hemorrhagic fever outbreaks in humans. Emerging Health Threats Journal 5: 9134 Olson SH, Reed P, Ondzie A, Cameron K, Joly D (2012) Maximizing nonhuman primate fecal sampling in the Republic of Congo. Journal of Wildlife Diseases 48: 888-898

Pigott DM, Golding N, Mylne A, Huang Z, Henry AJ, Weiss DJ et al.(2014) Mapping the zoonotic niche of Ebola virus disease in Africa. Elife 3: e04395.

Qiu X, Fernando L, Alimonti JB, Melito PL, Feldmann F, Dick D, Ströher U, Feldmann H, Jones SM (2009) Mucosal immunization of cynomolgus macaques with the 
VSVDeltaG/ZEBOVGP vaccine stimulates strong ebola GP-specific immune responses. PLoS One 4: e5547.

Rabinowitz PM, Kock R, Kachani M, Kunkel R, Thomas J, Gilbert J et al. (2013) Toward proof of concept of a one health approach to disease prediction and control. Emerging Infectious Diseases 19: doi:10.3201

Reed PE, Mulangu S, Cameron KN, Ondzie AU, Joly D, Bermejo M et al. (2014) A new approach for monitoring ebolavirus in wild great apes. PLoS Neglected Tropical Diseases 8: e3143.

Ringen K, Landrigan PJ, Duffy R, Melius J, McDiarmid MA (2015) Occupational safety and health protections against Ebola virus disease. American Journal of Industrial Medicine 58: 703-14

Robbins MM, Gray M, Fawcett KA, Nutter FB, Uwingeli P, Mburanumwe I et al. (2011) Extreme conservation leads to recovery of the Virunga mountain gorillas. PLoS One 6: e19788.

Rougeron V, Feldmann H, Grard G, Becker S, Leroy EM (2015) Ebola and Marburg haemorrhagic fever. Journal of Clinical Virology 64: 111-119.

Rouquet P, Froment JM, Bermejo M, Kilbourn A, Karesh W, Reed P et al. (2005) Wild animal mortality monitoring and human Ebola outbreaks, Gabon and Republic of Congo, 2001-2003. Emerging Infectious Diseases 11: 283-290.

Ryan SJ, Jones JH, Dobson AP (2013) Interactions between social structure, demography, and transmission determine disease persistence in primates. PLoS One 8: e76863.

Ryan SJ, Walsh, PD (2011) Consequences of non-intervention for infectious disease in African great apes. PLoS One 6: e29030. 
Stanley DA, Honko AN, Asiedu C, Trefry JC, Lau-Kilby AW, Johnson JC et al. (2014) Chimpanzee adenovirus vaccine generates acute and durable protective immunity against ebolavirus challenge. Nature Medicine 20: 1126-9

Towner JS, Sealy TK, Khristova ML, Albarino CG, Conlan S, Reeder SA et al. (2008) Newly discovered ebola virus associated with hemorrhagic fever outbreak in Uganda. PLoS Pathogen 4: e1000212.

Travis DA, Hungerford L, Engel GA, Jones-Engel L (2006) Disease risk analysis: a tool for primate conservation planning and decision making. American Journal of Primatology 68: $855-867$.

Travis DA, Lonsdorf EV, Mlengeya T, Raphael J (2008) A science-based approach to managing disease risks for ape conservation. American Journal of Primatology 70: 745-750.

Tsuda Y, Caposio P, Parkins CJ, Botto S, Messaoudi I, Cicin-Sain L, Feldmann H, Jarvis MA (2011) A replicating cytomegalovirus-based vaccine encoding a single Ebola virus nucleoprotein CTL epitope confers protection against Ebola virus. PLoS Neglected Tropical Diseases 5: e1275.

Viana M, Mancy R, Biek R, Cleaveland S, Cross PC, Lloyd-Smith JO, Haydon DT (2014) Assembling evidence for identifying reservoirs of infection. Trends in Ecology and Evolution 29: 270-279.

Vigilant L, Hofreiter M, Siedel H, Boesch C (2001) Paternity and relatedness in wild chimpanzee communities. Proceedings of the National Acadademy of Sciences of the United States of America, 98: 12890-12895.

Vogel G (2006) Ecology. Tracking Ebola's deadly march among wild apes. Science 314: $1522-1523$. 
Waldman L (2015) Urbanisation, the Peri-urban growth and Zoonotic disease. Institute of Developmental Studies Practice Paper in Brief 22.

Walsh PD, Tutin CEG, Oates, JF, Baillie JEM, Maisels F, Stokes EJ, Gatti S, Bergl RA, Sunderland-Groves J, Dunn A (2007) IUCN Red List of Threatened Species. http://www.iucnredlist.org/details/9404/0

Walsh PD, Bermejo M, Rodriguez-Teijeiro JD (2009) Disease avoidance and the evolution of primate social connectivity: Ebola, bats, gorillas, and chimpanzees. In Huffman MA, Chapman CA (eds) Primate Parasite Ecology: The Dynamics and Study of Host-Parasite Relationships, 183-198. Cambridge University Press, Cambridge, UK.

Walsh PD, Breuer T, Sanz C, Morgan D, Doran-Sheehy D (2007) Potential for Ebola transmission between gorilla and chimpanzee social groups. The American Naturalist 169: 684-689.

Walsh MG, Haseeb MA (2015) The landscape configuration of zoonotic transmission of Ebola virus disease in West and Central Africa: interaction between population density and vegetation cover Peer J 3: e735

Warfield KL, Goetzmann, JE, Biggins JE, Kasda MB, Unfer RC, Vu H, Aman MJ, Olinger GG Jr, Walsh PD (2014) Vaccinating captive chimpanzees to save wild chimpanzees. Proceedings of the National Acadademy of Sciences of the United States of America 111: 8873-8876.

Warren Y, Williamson EA (2004) Transport of dead infant mountain gorillas by mothers and unrelated females. Zoo Biology 23: 375-378.

Wittmann TJ, Biek R, Hassanin A, Rouquet P, Reed P, Yaba P, Pourrut X, Real LA, Gonzales JP, Leroy EM (2007) Isolates of Zaire ebolavirus from wild apes reveal genetic 
lineage and recombinants. Proceedings of the National Academy of Sciences of the United States of America 104: 17123-17127.

Wong G, Audet J, Fernando L, Fausther-Bovendo H, Alimonti J B, Kobinger GP, Qiu X (2014) Immunization with vesicular stomatitis virus vaccine expressing the Ebola glycoprotein provides sustained long-term protection in rodents. Vaccine 32: 5722-5729.

\section{FIGURE LEGENDS}

Figure 1. Locations of Ebola-positive great ape carcasses and points of origin of human Ebola virus disease outbreaks in the tropical belt of Africa (dots). The larger ovals in Gabon and Republic of Congo represent three and five outbreaks, respectively (Pigott et al. 2014, Anonymous 2015c). CAR=Central African Republic, DRC=Democratic Republic of Congo.

Figure 2. Schematic presentation of the principles of Ebola vaccination strategies in great apes. The bats represent any possible source of Ebola infection. The open dots and circles illustrate individuals and groups in the ape population: Dark grey/black=Ebola infected, grey=vaccinated, white=naïve. a) The principle of a self-spreading vaccine. Long arrows indicate introduction of vector virus, the short grey arrows show subsequent spread and the short white arrows indicate potential routes of further spread. b) Vaccination of specific groups, e.g. habituated groups. c) Ring vaccination in the event of an EVD outbreak. d) Vaccination of the entire population. 